\title{
Characteristics of persons with spinal cord injury who drive in Malaysia and its barriers: a cross sectional study
}

\author{
Richard Chee Houw Lee ${ }^{1}$ Nazirah Hasnan ${ }^{1,2}$ - Julia Patrick Engkasan ${ }^{1,2}$
}

Received: 29 June 2017 / Revised: 12 October 2017 / Accepted: 26 October 2017 / Published online: 29 December 2017

(c) International Spinal Cord Society 2018

\begin{abstract}
Study design Cross sectional study.

Objectives To determine the prevalence, characteristics of and barriers to driving among persons with a spinal cord injury (SCI).

Setting SCI Rehabilitation Clinic, University Malaya Medical Centre (UMMC).

Methods This is a questionnaire-based study on persons with SCI who attended the UMMC SCI Rehabilitation Clinic between June 2015 and November 2016. The questionnaire comprised demographic data, clinical characteristics, driving variables, Spinal Cord Independence Measure III, WHOQOL-BREF, and Craig Handicap Assessment and Reporting Technique Short Form. Malaysians aged greater than 18 years old with any etiology and levels of SCI, had no other physical disabilities and not suffering from progressive illness were recruited. A single investigator administered the questionnaire via face-to-face interviews.

Results A total of 160 participants were included in this study. Overall, 37\% of persons with SCI drove and owned a modified vehicle. Almost half of persons with paraplegia (47\%) drove, but only $12 \%$ of tetraplegia did. A majority (93\%) of those who drove aged below 60 years, and had higher level of independence in activity of daily living. More drivers (81\%) compared to nondrivers (24\%) were employed; drivers also reported better community reintegration and quality of life. Three commonest barriers to driving included medical reasons (38\%), fear and lack of confidence (17\%), and inability to afford vehicle modifications (13\%). Conclusions The percentage of persons with SCI driving post injury is low. Based on the findings of this study, more efforts are needed to motivate and facilitate persons with SCI to drive.
\end{abstract}

\section{Introduction}

In the recent years, spinal cord injury (SCI) rehabilitation services have evolved beyond improving independence of daily living and preventing SCI-related complications to improving patients' community participation. Participation is defined as involvement in a life situation, which includes learning, communication, mobility, self-care, and domestic and community life [1]. The availability of transportation and ability to drive have a positive effect on social activity

Julia Patrick Engkasan

Julia@ummc.edu.my

1 Department of Rehabilitation Medicine, Faculty of Medicine, University of Malaya, 50603 Kuala Lumpur, Malaysia

2 Department of Rehabilitation Medicine, University of Malaya Medical Centre, 59100 Kuala Lumpur, Malaysia and participation [2-4]. Several studies also highlighted persons with SCI who drive reported better quality of life, better mental well-being and improved chances of employment [5-8]. Therefore, the ability to drive after SCI is an important aspect of SCI rehabilitation. The prevalence of driving after SCI ranges from 36 to $61 \%$ [9-11]. In the United States, Norweg et al. [9]. reported a prevalence rate of $36 \%$, while Netherlands reported a higher rate of $61 \%$ [11]. In Japan, Kiyono et al. [10]. studied only persons with tetraplegia and found that $53 \%$ drive. Significant predictors for driving a modified vehicle post-SCI include being married at injury, younger age at injury, holding a bachelor's degree or higher before injury, paraplegia, longer years post injury and male gender [9].

Previous literatures have revealed little information about driving with a disability in Malaysia. Cars and motorcycles are the two most commonly used modes of transport for the Malaysian population. Modified cars are usually recommended to persons with SCI due to safety implications and 
a proper seating system. However, due to financial constraint, modified 3-wheeled motorcycles with a carriage are occasionally chosen. There is only one study that reports on driving status after SCI in Malaysia; [4] however the study was underpowered and barriers of driving among person with SCI were not studied.

Prevalence, challenges and barriers of driving among Malaysian with SCI remains unknown to date. Hence, we aimed to determine the prevalence of driving post-SCI among persons with SCI, their demographics and barriers to driving. The secondary objectives were to describe the types of vehicles used and the participants' current employment status, community reintegration, quality of life and independence level.

\section{Methods}

\section{Ethical consideration}

The study was approved by the institution's Medical Research Ethics Committee (20154-1252). Each participant received and read the patient's information sheet, and written consent was obtained prior to the interviews.

\section{Study design and setting}

This was a cross-sectional study conducted at University of Malaya Medical Centre (UMMC), a 1000 bedded university hospital located in urban city, Kuala Lumpur. The Spinal Cord Injury Rehabilitation (SCIR) services consist of acute, post-acute and long-term rehabilitation care. The SCIR clinic provides long-term follow up of SCI patients; most patients come for regular follow up appointment for health monitoring and treatment.

\section{Participants}

All persons with SCI who attended the outpatient SCI Rehabilitation Clinic were screened for study inclusion for a period of 18 months (June 2015 to November 2016). The inclusion criteria were as follows: persons with SCI regardless of the level and aetiology; and aged over 18 years at the time of study. Persons with physical disabilities other than SCI (hemiplegia, upper limb amputation or any other physical impairments), cognitive impairment, minimal or no neurological deficit after SCI and those with progressive spinal cord pathology were excluded.

\section{Research instruments}

This study utilised a five-part questionnaire for collecting the relevant data. The first and second parts are specifically designed, taking into consideration the aims and objectives of this study. It consists of demographic data and clinical characteristics and patients' driving variables $[12,13]$. The third part measures patients' independence using the mobility subset of Spinal Cord Independence Measure III (SCIM III) [14]. There are nine mobility items in this subset and scores ranges from 0 to 40 ; higher the scores indicate higher independence in mobility.

The fourth part measures patients' quality of life using WHOQOL-BREF [15]; WHOQOL-BREF consisted of four components (physical health, psychology health, socioeconomic health, and environmental health) and has 26 questions with answers based on five-point scale. The higher the score the better quality of life is.

The final part measures the level of community reintegration using mobility, occupation, and social integration domains of Craig Handicap Assessment and Reporting Technique Short Form (CHART-SF) [16]. CHART-SF was designed to measure degree of handicap resulting from disability and each domain could have a maximum of 100 . Score of 100 indicate no handicap and $<100$ indicate some handicap.

A single investigator administered the questionnaire personally (via face-to-face interviews); the average length of time used for each interview was $30 \mathrm{~min}$.

\section{Analysis}

Descriptive statistics was employed to summarise the demographic data between drivers and non-drivers and barriers to driving. Age group were grouped into three groups which were $18-29,30-59$, and 60 years old and above, consistent with previous study [9]. Chi-square was used to test for significant differences between categorical variable and driving status. A $p$ value level of $<0.5$ was considered significant. SPSS version 23.0 for Windows was used for statistical analysis.

\section{Results}

\section{Participants characteristics}

A total of 165 participants met the inclusion criteria and exclusion but only 160 subjects (97\%) agreed to participate. The majority of participants were males (114 out of 160, $71 \%$ ), aged $30-59$ years (106 out of $160,66 \%$ ), single, had paraplegia $(112$ out of $160,70 \%)$ and sustained traumatic SCI (114/71\%). Approximately a third (37\%) drove following their SCI; Table 1 illustrates the differences in demographics and illness characteristics between those who drove and those who did not. 
Table 1 Demographic and injury characteristics of participants according to driving status $(N=160)$

\begin{tabular}{|c|c|c|c|}
\hline Variables & Drive & $\begin{array}{l}\text { Do not } \\
\text { drive }\end{array}$ & $P$ value* \\
\hline Total number of participants (\%) & $59(37 \%)$ & $101(63 \%)$ & \\
\hline \multicolumn{4}{|l|}{ Current age group } \\
\hline $18-29$ & $10(36 \%)$ & $18(64 \%)$ & \multirow[t]{3}{*}{$<0.05^{*}$} \\
\hline $30-59$ & $45(42 \%)$ & $61(58 \%)$ & \\
\hline$\geq 60$ & $4(15 \%)$ & $22(85 \%)$ & \\
\hline \multicolumn{4}{|l|}{ Gender } \\
\hline Male & $42(37 \%)$ & $72(63 \%)$ & \multirow[t]{2}{*}{$>0.05$} \\
\hline Female & $17(37 \%)$ & $29(63 \%)$ & \\
\hline \multicolumn{4}{|l|}{ Race } \\
\hline Malay & $17(33 \%)$ & $34(67 \%)$ & \multirow[t]{3}{*}{$>0.05$} \\
\hline Chinese & $34(38 \%)$ & $55(62 \%)$ & \\
\hline Indian & $8(40 \%)$ & $12(60 \%)$ & \\
\hline \multicolumn{4}{|l|}{ Marital status } \\
\hline Single & $36(39 \%)$ & $57(61 \%)$ & \multirow[t]{3}{*}{$>0.05$} \\
\hline Married & $20(36 \%)$ & $35(64 \%)$ & \\
\hline Divorced/Widow/Widower & $3(25 \%)$ & $9(75 \%)$ & \\
\hline \multicolumn{4}{|l|}{ Educational level } \\
\hline Secondary school or lower & $40(35 \%)$ & $75(65 \%)$ & \multirow[t]{3}{*}{$>0.05$} \\
\hline Diploma & $8(50 \%)$ & $8(50 \%)$ & \\
\hline Bachelor degree or higher & $11(38 \%)$ & $18(62 \%)$ & \\
\hline \multicolumn{4}{|l|}{ Neurological level of injury } \\
\hline Cervical & $6(12 \%)$ & $42(88 \%)$ & \multirow[t]{3}{*}{$<0.05^{*}$} \\
\hline Thoracic & $38(45 \%)$ & $47(55 \%)$ & \\
\hline Lumbar & $15(56 \%)$ & $12(44 \%)$ & \\
\hline \multicolumn{4}{|l|}{ Type of impairment } \\
\hline Paraplegia & $53(47 \%)$ & $59(53 \%)$ & \multirow[t]{2}{*}{$<0.05^{*}$} \\
\hline Tetraplegia & $6(12 \%)$ & $42(88 \%)$ & \\
\hline \multicolumn{4}{|l|}{ Etiology of injury } \\
\hline Traumatic & $44(39 \%)$ & $70(61 \%)$ & \multirow[t]{2}{*}{$>0.05$} \\
\hline Non traumatic & $15(33 \%)$ & $31(67 \%)$ & \\
\hline \multicolumn{4}{|l|}{ Drove prior to injury } \\
\hline Yes & $34(35 \%)$ & $64(65 \%)$ & \multirow[t]{2}{*}{$>0.05$} \\
\hline No & $25(40 \%)$ & $37(60 \%)$ & \\
\hline
\end{tabular}

*Significant difference between groups $(P<0.05)$

Age group and neurological impairment are statistically significant factors associated with driving. Participants aged below 60 years are more likely to drive compared with those aged 60 and more. With regard to neurological levels, the majority of tetraplegia (88\%) do not drive and approximately half of paraplegia drove. The highest level of driving in this study is C5 AIS B, in which the participant was able to drive independently but needed assistance to transfer from the wheelchair into the car. There was no significant difference in gender, race, marital status, mechanism of injury, educational level, and history of driving prior to SCI between drivers and non-drivers.
Majority of those who drive (88\%) used their transport at least 5 days a week.

\section{Vehicle modifications}

Among those who drove, 48 participants $(81 \%)$ drove a modified car; 10 (17\%) drove modified motorcycles, while one $(2 \%)$ drove both. All of the participants used cars with automatic transmission; modifications used by study participants include hand operated brake and accelerators with and without installations of steering knobs; $74 \%$ and $24 \%$, respectively. As for motorcycle, there was only one type of modification, which was the three-wheeled motorcycle with a side carriage to transport the wheelchair.

\section{Barriers to driving}

The reasons for not driving given by participants are health problems $(38 \%)$, followed by fear and lack of confidence (17\%), inability to afford the cost of modifications (13\%), prefer not to drive $(6 \%)$, prohibited by family $(5 \%)$, and transportation easily available (3\%). Fourteen of those who gave health reasons have tetraplegia and stated their physical impairment as the main reason for not driving. The other 15 participants who did not drive have paraplegia and quoted pain (shoulder, wrist, and hand) prevented them from driving.

A total of 17 participants cited fear and lack of confidence as reasons for preventing them from driving; five have tetraplegia and 12 have paraplegia. Out of the 17, ten were afraid because they were traumatised by previous motor vehicle accidents that caused their SCI. Meanwhile, seven did not feel confident in operating a vehicle and feared for their safety. Participants in the category 'intended to drive' $(17.8 \%)$, planned to do so within two years from the time of interview. Three were waiting for their vehicle modifications to be done and 10 were undergoing driving assessment. Five were busy with their personal life or work and did not have time to undergo driving assessment.

\section{Employment, community reintegration, quality of life and independence level}

Table 2 shows the comparison between drivers and nondrivers with regards to their current employment, community reintegration, quality of life, and independence level. A majority of drivers $(81 \%)$ are employed at the time of study compared to $24 \%$ among non-drivers. Drivers reported higher score in all three components (mobility, occupation, and social integration) of the CHART-SF compared to nondrivers. Likewise, those who drive also reported higher score in all domains of WHOQOL-BREF (physical health, 
Table 2 Driving status and current employment, community reintegration, quality of life and independence according to driving status

\begin{tabular}{|c|c|c|}
\hline Variables (Instruments) & $\begin{array}{l}\text { Driving } \\
(N=59)\end{array}$ & $\begin{array}{l}\text { Not driving } \\
(N=101)\end{array}$ \\
\hline \multicolumn{3}{|l|}{ Employment $(n)$} \\
\hline Working & 48 & 27 \\
\hline Not working & 11 & 74 \\
\hline \multicolumn{3}{|c|}{ Community integration Score (CHART -SF) (Median, (IQR)) } \\
\hline Mobility & $100(97-100)$ & $63(42-90)$ \\
\hline Occupation & $100(50-100)$ & $5(0-45)$ \\
\hline Social & $100(92-100)$ & $97(71-100)$ \\
\hline \multicolumn{3}{|l|}{ Quality of Life (WHOQOL-BREF) } \\
\hline Physical health (mean + SD) & $69+16$ & $44+16$ \\
\hline Psychology health (median (IQR)) & $69(63-75)$ & $38(25-50)$ \\
\hline Social relationship (median (IQR)) & $69(56-75)$ & $44(25-62)$ \\
\hline Environment (median (IQR)) & $75(69-81)$ & $32(25-47)$ \\
\hline \multicolumn{3}{|l|}{ Independence level } \\
\hline $\begin{array}{l}\text { Mobility subset of SCIM III (Median } \\
\text { (IQR)) }\end{array}$ & $18(18-18)$ & $16(5-16)$ \\
\hline
\end{tabular}

psychological health, social relationships, and environment) and in the mobility subset of SCIM III.

\section{Discussion}

This study is the only study in Malaysia to describe the demographics of drivers, barriers to driving and vehicle modifications. We found $37 \%$ of persons with SCI drive, and this is similar to findings observed by Norweg et al. [9]. However, the current study reflects the driving rate of SCI population in an urban area where vehicle modification, driving assessment and teaching facilities are readily available. Post et al. [11] in the Netherlands reported a higher prevalence of $61 \%$. This could be due to the availability of financial assistance for vehicle modifications as provided by their law; according to the 1994 Disabled Act (WVG), municipalities are obliged to pay for the cost of vehicle modifications [17].

In this study, participants of the younger age group $(<60$ years old) were more likely to drive. This study concurs with the findings of Norweg et al. [9], who also reported a similar trend. The mean age of Post et al.'s [11] study population is 39.4 years, indicating a younger study population; this may also explains the higher percentage of people driving in the Dutch study.

It is expected that persons with cervical SCI have more physical impairments and would face difficulties to manage a vehicle. However, Kiyono et al. [10] reported that nearly half $(48 \%)$ of their participants with tetraplegia could drive compared with $13 \%$ in our study, and $26 \%$ in the work of Norweg et al. [9]. Half of the participants in Kiyono et al. [10] study had hand reconstruction surgery, which probably led to the higher driving rate among participants tetraplegia in their study. It is also important to note $11 \%$ of Norweg et al. [9] study population who drove are of C4 level, compared with C6 in Kiyono et al. [10] and C5 in the current study. It is possible that the type of vehicle used by participants in Norweg et al.'s study contributed to this higher rate.

Vehicle modifications vary from country to country. In Denmark, there are hand operated brakes and accelerators, vehicle lift systems, adapted seating, and adapted heating systems [19]. Similarly, in Sweden, common vehicle modifications include power steering, hand-controlled levers for brakes and accelerators, adapted driver's seats, ramps or lift systems for wheelchairs, spinner knobs or other handles for the steering wheel, electrically operated side windows and electrically operated rearview mirrors [20]. In Malaysia, the modifications available are rather limited; consisting of only hand-controlled cars and threewheeled motorcycles [4]. Although a motorcycle would be a cheaper option and easier to manoeuvre, the authors of this study are of the opinion that a modified car is preferable to motorcycle because it is safer and has a better seating system. A person who rides a motorcycle needs to have good trunk balance and the ability to transfer from a wheelchair to a higher level as motorcycle seat is generally at a higher level than a wheelchair. To the authors' knowledge, modified vehicles that enable driving in a wheelchair are not available in Malaysia. These types of modification are helpful as they do away with the need to carry the wheelchair into the vehicle.

According to the International Classification of Functioning, Disability and Health (ICF), barriers to driving could be divided into body function and structure, environmental and personal factors [1]. The commonest reason given by those who do not drive are health reasons (body function and structure). Many participants with tetraplegia felt they could not drive because of their neurological level of injury. This is understandable given that driving requires considerably good hand function. Musculoskeletal pain such as shoulder, hand, or wrist pain is another health reason identified as a deterrent against driving. Chronic wrist and shoulder pain are common in people with SCI and are reported to occur in half of SCI population [21]. This study does not explore further how musculoskeletal pain prevents a person from driving; pain could interfere with transfer into the vehicle, carrying the wheelchair, or actual driving activities.

The second commonest reason for not driving is fear and lack of confidence (personal factors). This is quite normal as post-traumatic stress disorder post-motor vehicle accidents 
are common and can be disabling [22]. The third most common reason is inability to purchase or modify the vehicle (personal factor). People with a spinal cord injury have to bear additional costs such as purchase of equipment, medications, catheters, diapers and family needs; as such, spending on a vehicle or modifications may not be a priority. In Victoria, Australia, employees who are injured in the workplace are entitled to compensation to modify their cars for daily usage [23].

Although previous studies have inferred from their results that driving leads to a higher likelihood of being employed, greater degree of community participation and better quality of life, these are cross-sectional studies that have limited ability to prove causation $[3,5,9,10]$. Likewise Jang et al. of Taiwan, reported $81 \%$ of their subjects who were independent with public or private transportation were employed [24]. Although our study also found that majority of those who drive are employed, it is not possible to infer causation from a cross-sectional study. At present most of the conventional jobs in Malaysia still require a person to get to the workplace, thus personal mobility is very important. However, with increasing opportunity to work from home and the ability to be self-employed, this situation might change in the future.

Similar to previous studies [2, 9], this study also found that participants who drive reported a greater degree of social and community participation. This is important since community reintegration is considered the ultimate longterm goal of rehabilitation for persons with SCI [25]. Kiyono et al. [10] also found similar results where half of their participants who drove were also involved in sports activities whilst Franceschini et al. [8] reported that driving facilitated access to educational, social, and recreational facilities.

It is expected that a person needs to be independent to be able to drive alone. It still holds in most cases, but technology enables people with lesions as high as $\mathrm{C} 4$ to drive [9]. This could be made possible with the facility of wheelchair driving and advanced control system, although how the actual driving occurs in this population was not discussed in the article. Kiyono et al. [10] investigated functional ability such as bed transfer, toilet transfer, tub transfer and lower body dressing with driving; they found the ability of toilet transfer is closely related to the ability to drive independently, including stowing the wheelchair into the vehicle.

This study is not without limitations; it is a crosssectional study and therefore, it is not possible to prove that driving has a causal effect on the variables such as employment, community participation and quality of life. This study was conducted in a tertiary centre, which offers driving rehabilitation and vehicle modifications are readily available; thus the results generated from this study are likely an overestimate of the Malaysian driving after SCI. It is also not possible to determine if the study population is representative of the Malaysian SCI demography, as there is lack of such information. The strengths of this study include these aspects: use of a single interviewer eliminated interrater bias; the questionnaires used were validated for persons with SCI; and the response rate of the study was good. There are many potential future studies, which can be considered. The scope of this study should be expanded nationwide, as this would better represent the country and provide more generalisable data. The research can also look into other patterns of driving, such as when do people start driving, the obstacles they faced in the process of learning or returning to driving, and the cost associated with returning to driving or learning to drive. The causal relationship between driving and possible benefits such as employment, quality of life and community integration could be ascertained by performing a large cohort study with prospectively collected data in which all possible confounders are initially identified through directed acyclic graphs which are then used to determine the core confounders that need to be adjusted for [26]. A qualitative study could be carried out to explore the positive and negative experiences of driving in order to understand the reasons or motivation why they decide to drive or otherwise, as well as their satisfaction with driving.

In conclusion, the driving rate is low in this study population; majority of those who drive are younger than 60 years old and have paraplegia. Participants who drive reported better community reintegration and better quality of life. The barriers to return to driving are modifiable; driving post-SCI could be improved by providing driving rehabilitation services and workable financial plans to buy or modify vehicles.

Acknowledgements The study was funded by University of Malaya Research Grant (RP035B-15HTM). Special thanks to Dr Lee Keng Yee from Clinical Epidemiology Unit, National Clinical Research Centre, Ministry of Health Malaysia for her effort to proofread this manuscript.

\section{Compliance with ethical standards}

Conflict of interest The authors declare that they have no competing interests.

\section{References}

1. World Health Organization. Towards a common language for functioning, disability and health: ICF. Geneva: World Health Organization; 2002.

2. Carpenter C, Forwell SJ, Jongbloed LE, Backman CL. Community participation after spinal cord injury. Arch Phys Med Rehabil. 2007;88:427-33. 
3. Noreau L, Dion S, Vachon J, Gervais M, Laramee M. Productivity outcomes of individuals with spinal cord injury. Spinal Cord. 1999;37:730-6.

4. Ramakrishnan K, Chung T, Hasnan N, Abdullah S. Return to work after spinal cord injury in Malaysia. Spinal Cord. 2011;49:812-6.

5. Conroy L, McKenna K. Vocational outcome following spinal cord injury. Spinal Cord. 1999;37:624-33.

6. Tate D, Forchheimer M, Maynard F, Dijkers M. Predicting depression and psychological distress in persons with spinal cord injury based on indicators of handicap. Am J Phys Med Rehabil. 1994;73:175-83.

7. Siosteen A, Lundqvist C, Blomstrand C, Sullivan L, Sullivan M. The quality of life of three functional spinal cord injury subgroups in a Swedish community. Paraplegia. 1990;28:476-88.

8. Franceschini M, Di Clemente B, Rampello A, Nora M, Spizzichino L. Longitudinal outcome 6 years after spinal cord injury. Spinal Cord. 2003;41:280-5.

9. Norweg A, Jette A, Houlihan B, Ni P, Boninger M. Patterns, predictors, and associated benefits of driving a modified vehicle after spinal cord injury: findings from the National Spinal Cord Injury Model Systems. Arch Phys Med Rehabil. 2011;92:477-83.

10. Kiyono Y, Hashizume C, Matsui N, Ohtsuka K, Takaoka K. Cardriving abilities of people with tetraplegia. Arch Phys Med Rehabil. 2001;82:1389-92.

11. Post M, van Asbeck F, van Dijk A, Schrijvers A. Services for spinal cord injured: availability and satisfaction. Spinal Cord. 1997;35:109-15.

12. Boulias C, Meikle B, Pauley T, Devlin M. Return to driving after lower-extremity amputation. Arch Phys Med Rehabil. 2006;87:1183-88.

13. Engkasan J, Ehsan F, Chung T. Ability to return to driving after major lower limb amputation. J Rehabil Med. 2012;44:19-23.

14. Catz A, Itzkovich M, Agranov E, Ring H, Tamir A. SCIM-spinal cord independence measure: a new disability scale for patients with spinal cord lesions. Spinal Cord. 1997;35:850-6.
15. World Health Organization. WHOQOL-BREF: Introduction, administration, scoring and generic version of the assessment. Geneva, 1996

16. Whiteneck, G. Validated measures of participation and the environment from Craig hospital: CHART and CHIEF. United Nations International Seminar on the Measurement of Disability. New York, 2001. Available from: https://unstats.un.org/unsd/disa bility/pdfs/ac.81-4-1.pdf. (Accessed 15 October 2016).

17. Michailakis D. Government implementation of the standard Rules As Seen By Member Organizations of Disabled Peoples' International. Netherlands: National Disability Council; 1997.

18. Welch R, Lobley S, O'Sullivan S, Freed M. Functional independence in quadriplegia: critical levels. Arch Phys Med Rehabil. 1986;67:235-40.

19. Biering-Sorensen F, Hansen RB, Biering-Sorensen J. Mobility aids and transport possibilities 10-45 years after spinal cord injury. Spinal Cord. 2004;42:699-706.

20. Henriksson P, Peters B. Safety and mobility of people with disabilities driving adapted cars. Scand J Occup Ther. 2004;11:54-61.

21. Dalyan M, Cardenas D, Gerard B. Upper extremity pain after spinal cord injury. Spinal Cord. 1999;37:191-5.

22. Mayou R, Bryant B, Duthie R. Psychiatric consequences of road traffic accidents. Br Med J. 1993;307:647-51.

23. Workplace Injury Rehabilitation and Compensation Act (WIRC Act) 2013. Available from: http://www.legislation.vic.gov.au. (Accessed on 15 October 2016).

24. Jang Y, Wang Y, Wang J. Return to work after spinal cord injury in Taiwan: the contribution of functional independence. Arch Phys Med Rehabil. 2005;86:681-86.

25. Chan S, Chan A. User satisfaction, community participation and quality of life among Chinese wheelchair users with spinal cord injury: a preliminary study. Occup Ther Int. 2007;14:123-43.

26. Shrier I, Platt RW. Reducing bias through directed acyclic graphs. BMC Med Res Methodol. 2008;8:7. 